\title{
Heat stability of reconstituted, protein-standardized skim milk powders
}

\author{
V. Sikand, ${ }^{*}$ P. S. Tong, ${ }^{* 1}$ and J. Walker† \\ *Dairy Products Technology Center, and \\ †Department of Statistics, California Polytechnic State University, San Luis Obispo 93407
}

\section{ABSTRACT}

We determined the effects of standardization material, protein content, and $\mathrm{pH}$ on the heat stability of reconstituted milk made from low-heat $(\mathrm{LH})$ and medium-heat (MH) nonfat dry milk (NDM). Low-heat and MH NDM were standardized downward from $35.5 \%$ to 34,32 , and $30 \%$ protein by adding either edible lactose powder (ELP) or permeate powder (PP) from skim milk ultrafiltration. These powders were called standardized skim milk powders (SSMP). The LH and MH NDM and SSMP were reconstituted to $9 \%$ total solids. Furthermore, subsamples of reconstituted NDM and SSMP samples were set aside to measure heat stability at native (unadjusted) $\mathrm{pH}$, and the rest were adjusted to $\mathrm{pH} 6.3$ to 7.0. Heat stability is defined as heat coagulation time at $140^{\circ} \mathrm{C}$ of the reconstituted $\mathrm{LH}$ or $\mathrm{MH}$ NDM and SSMP samples. The entire experiment was replicated 3 times at unadjusted $\mathrm{pH}$ values and 2 times at adjusted $\mathrm{pH}$ values. At an unadjusted $\mathrm{pH}$, powder type, standardization material, and protein content influenced the heat stability of the samples. Heat stability for reconstituted LH NDM and SSMP was higher than reconstituted MH NDM and SSMP. Generally, decreased heat stability was observed in reconstituted LH or MH SSMP as protein content was decreased by standardization. However, adding ELP to MH SSMP did not significantly change its heat stability. When $\mathrm{pH}$ was adjusted to values between 6.3 and 7.0, powder type, standardization material, and $\mathrm{pH}$ had a significant effect on heat stability, whereas protein content did not. Maximum heat stability was noted at $\mathrm{pH} 6.7$ for both reconstituted LH NDM and SSMP samples, and at $\mathrm{pH} 6.6$ for both reconstituted MH NDM and SSMP samples. Furthermore, for samples with adjusted $\mathrm{pH}$, higher heat stability was observed for reconstituted LH SSMP containing PP compared with reconstituted milk from LH SSMP containing ELP. However, no statistical difference was observed in the heat stability of reconstituted milk from MH NDM and MH SSMP

Received February 1, 2010.

Accepted September 3, 2010.

${ }^{1}$ Corresponding author: ptong@calpoly.edu samples. We conclude that powder type ( $\mathrm{LH}$ or $\mathrm{MH})$ and effect of standardization material (ELP or PP) can help explain differences in heat stability. The difference in the heat stability of powder type may be associated with the difference in the $\mathrm{pH}$ of maximum heat stability and compositional differences in the standardization material (ELP or PP).

Key words: heat stability, nonfat dry milk, protein standardization

\section{INTRODUCTION}

Milk and milk products are heat-treated to increase shelf life and ensure their safety for human consumption. Therefore, it is important that milk and milk powders used in various food applications be heat stable. Heat stability is defined as the ability of milk to withstand high temperatures without flocculation, gelation, or protein separation (Fox, 1982).

Heat stability of milk is mainly a function of its milk protein stability (Fox and Morrissey, 1977; O'Connell and Fox, 2003; Singh, 2004) and may be affected by protein content. Natural fluctuations in milk protein content (Harland et al., 1955; Ng-Kwai-Hang et al., 1987; Heck et al., 2009) have been reported throughout the seasons. Thus, protein standardization can be used to achieve more consistent protein content in dairy products (Jensen, 1988; Rattray and Jelen, 1996; Hardham, 1998; Sikand et al., 2008) and perhaps improve heat stability.

Milk protein standardization refers to the adjustment of protein content by the addition of small quantities of either retentate or permeate obtained from milk ultrafiltration (UF; Kieseker and Healey, 1996). Per Codex Alimentarius 207 (Codex Alimentarius, 1999), milk-derived permeate or lactose can be used to standardize protein content in the manufacturing of skim milk powder (SMP) for various food applications. Milk-derived permeate contains minerals, nonprotein nitrogen, and lactose, whereas lactose contains 99\% lactose and trace minerals. Green et al. (1984) found that low-molecular-weight components comprising nonprotein nitrogen appeared to be accounted for primarily by urea, AA, and ammonia. A positive cor- 
relation between nonprotein nitrogen and heat stability was observed in bovine milk (Robertson and Dixon, 1969) and goat milk (Mukherjee, 1993). Higher urea levels have been shown to increase the heat stability of milk (Robertson and Dixon, 1969; Muir and Sweetsur, 1976), which suggests that nonprotein nitrogen fraction plays a role in milk heat stability. Previous studies (Rattray and Jelen, 1996) using UF milk permeate to standardize milk protein content demonstrated high heat stability. Permeate is a coproduct of milk or whey protein concentrate manufacture, and it is possible that nonprotein nitrogen fraction in permeate used for milk protein standardization may improve heat stability.

Throughout the years, few studies have been conducted regarding milk protein standardization on heat stability. Newstead (1977) reported no influence of protein concentration on the heat stability of evaporated milk; however, during the majority of a season, enhanced evaporated milk heat stability was observed when permeate with low salt content was used for standardization. Therefore, it has been suggested that salt concentration appeared to play an important role in evaporated milk heat stability. Rattray and Jelen (1996) observed higher heat stability for skim milk protein content standardized with permeate from UF milk or permeate from UF sweet whey generated from skim milk treated with chymosin compared with unstandardized milk in the $\mathrm{pH}$ range of 6.4 to 7.1. The increased heat stability of protein-standardized milk was attributed to low calcium content. Protein-standardized skim milk with UF permeate from acid whey was observed to have decreased heat stability. This decreased heat stability was attributed to an increased ratio of soluble calcium to protein when compared with the UF permeate generated from the skim milk or sweet whey.

We hypothesized that protein standardization of NDM with edible lactose powder (ELP) may increase the heat stability of reconstituted standardized skim milk powder (SSMP) samples because ELP contains mainly lactose and very small amounts of minerals. However, protein standardization of NDM with permeate powder (PP) may increase the heat stability of reconstituted SSMP because PP contains nonprotein nitrogen.

Although some previous studies have been done on the heat stability of protein standardization of milk with UF permeate with respect to salt and protein concentration (Newstead, 1977; Anema et al., 1993; Rattray and Jelen, 1996), at this time, limited information is available on the effects of protein standardization of low-heat ( $\mathbf{H})$ and medium-heat (MH) NDM with either PP or ELP on heat stability. No single comprehensive study that compares the heat stability of different grades of milk powders in which protein contents are standardized with either ELP or PP is currently available.

The objective of this research was to determine the heat stability of reconstituted milk made from LH and MH NDM and SSMP at unadjusted and adjusted $\mathrm{pH}$ values. We provide 2 models describing how heat stability responds to differences in powder type, standardization material, and $\mathrm{pH}$ : the first is reconstituted milk from LH or MH NDM and SSMP at its unadjusted $\mathrm{pH}$, and the second is at $\mathrm{pH}$ adjusted to values from 6.3 to 7.0.

\section{MATERIALS AND METHODS}

\section{Materials, Sample Preparation, and Experimental Design}

Four 55-pound commercial bags of LH and MH NDM powder, ELP, and PP were obtained. The composition of these commercial ingredients is shown in Table 1. The samples were named LH-NDM when LH NDM powder was used to reconstitute milk and MH-NDM when MH NDM powder was used to reconstitute milk. Protein content (\%total $\mathrm{N} \times 6.38$ ) in $\mathrm{LH}$ or $\mathrm{MH} \mathrm{NDM}$ powder was standardized downward from $35.5 \%$ to 30 , 32 , and $34 \%$, either by adding a predetermined quantity of ELP or by adding PP (Sikand et al., 2008). These powders were called SSMP. Under Codex Alimentarius 207 (Codex Alimentarius, 1999), the standard limit for milk powders and standardization with milk permeate is up to $34 \%$ protein on an SNF basis. However, we studied reconstituted milk from LH SSMP and reconstituted milk from MH SSMP at or below $34 \%$ protein content to observe the trends of protein standardization of NDM powder on heat stability. A randomization procedure for standardizing the protein content of LH and MH NDM powder with ELP or PP was followed by blending LH or MH NDM with ELP or PP, respectively. The blended SSMP samples were named according to the level of protein $(30,32$, and $34 \%$ ) and material of standardization (ELP, PP); for example, when LH NDM powder was standardized with ELP to 30,32 , or $34 \%$ protein content, standardized samples were reconstituted to contain $9 \%$ TS and were referred to as LH30-ELP, LH32-ELP, and LH34-ELP, respectively. Collectively, these reconstituted standardized samples containing ELP (independent of protein content) were referred to as LH-ELP. Similarly, when LH NDM was standardized with PP to $30 \%, 32$, or $34 \%$ protein content, standardized samples were reconstituted to contain $9 \%$ TS and were referred to as LH30PP, LH32-PP, and LH34-PP, respectively. Collectively, these reconstituted standardized samples containing PP (independent of protein content), were referred to 


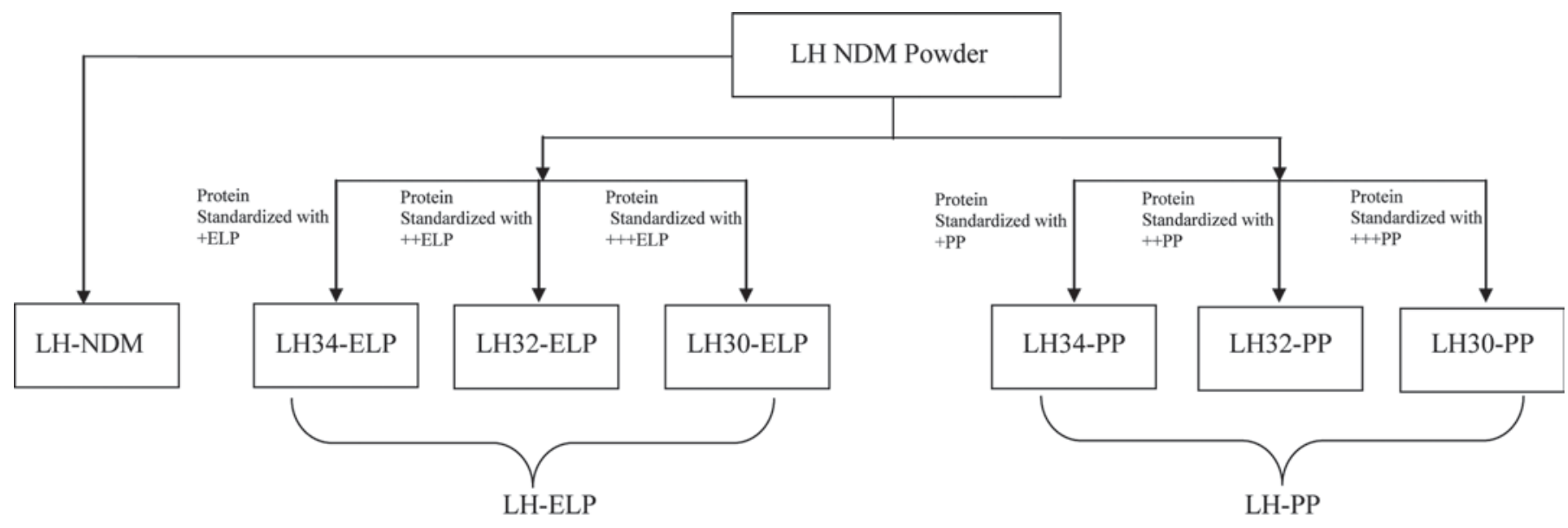

LH-SSMP

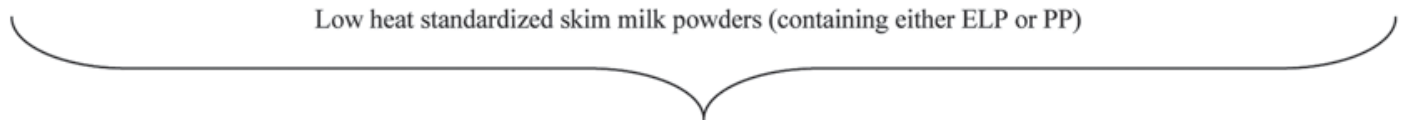

Figure 1. Flow diagram for low-heat NDM (LH-NDM) powder standardization with edible lactose powder (ELP) or permeate power (PP) to different protein contents.

as LH-PP. Furthermore, LH reconstituted standardized skim milk powder samples containing either ELP or PP, collectively, were referred to as LH-SSMP. Figure 1 is a flow diagram for LH NDM powder standardization used in this study. Table 2 contains the abbreviation or identification names used for reconstituted $\mathrm{LH}$ or $\mathrm{MH}$ NDM and SSMP samples.

\section{Analytical Methods}

Samples of LH NDM powder and MH NDM powder were analyzed for total nitrogen, moisture, ash, and fat content. Composition analyses were performed using the following AOAC (1995) methods: total nitrogen $(991.20 ; 33.2 .11)$, moisture $(990.20 ; 33.2 .44)$, ash (945.46; 33.2.10), and fat content (989.05; 33.2.26). Total calcium was determined by atomic absorption (model 3030B, Perkin-Elmer, Norwalk, CT) spectroscopy (Brooks et al., 1970).

\section{Heat Stability}

The reconstitution of $\mathrm{LH}$ and $\mathrm{MH}$ NDM and SSMP powder samples was performed in random order. The reconstitution was completed by stirring the samples with a magnetic stir bar in a beaker for $4 \mathrm{~h}$ at room temperature. After $4 \mathrm{~h}, 50 \mathrm{~mL}$ of each sample was set aside to measure heat stability at the unadjusted $\mathrm{pH}$. The remaining samples were adjusted to $\mathrm{pH} 6.3,6.4$, $6.5,6.6,6.7,6.8,6.9$, and 7.0 by dropwise addition of either $1 \mathrm{M} \mathrm{HCl}$ or $1 M \mathrm{NaOH}$. Samples were stored overnight in a refrigerator. These samples were brought to room temperature the next day and readjusted for $\mathrm{pH}$ as necessary.

Table 1. Composition of commercial low-heat and medium-heat NDM powder, edible lactose powder (ELP), and permeate powder $(\mathrm{PP} ; \mathrm{n}=3)^{1}$

\begin{tabular}{lccccc}
\hline $\begin{array}{l}\text { Sample } \\
\text { type }\end{array}$ & $\begin{array}{c}\text { CP } \\
\text { (wet basis) }\end{array}$ & Moisture & Ash & Fat & Lactose $^{2}$ \\
\hline LH-NDM & $35.4 \pm 0.28$ & $4.5 \pm 0.07$ & $7.68 \pm 0.02$ & $0.95 \pm 0.07$ & 51.47 \\
MH-NDM & $35.5 \pm 0.60$ & $3.35 \pm 0.28$ & $7.75 \pm 0.01$ & $0.88 \pm 0.13$ & 52.52 \\
ELP & ND & $1.75 \pm 0.21$ & $0.15 \pm 0.10$ & $0.00 \pm 0.0$ & 98.14 \\
PP & $2.40 \pm 0.28$ & $3.73 \pm 0.28$ & $7.69 \pm 0.02$ & $0.06 \pm 0.03$ & 86.12 \\
\hline
\end{tabular}

${ }^{1}$ Values given as percentage mean $\pm \mathrm{SD} . \mathrm{CP}=$ total nitrogen $\times 6.38 ; \mathrm{ND}=$ not detectable; $\mathrm{LH}-\mathrm{NDM}=$ lowheat NDM; MH-NDM = medium-heat NDM.

${ }^{2}$ Lactose calculated by difference. 
Table 2. Identification terms used for reconstituted NDM powders and standardized milk powders

\begin{tabular}{lll}
\hline $\begin{array}{l}\text { Low heat } \\
\text { powders }\end{array}$ & $\begin{array}{l}\text { Medium heat } \\
\text { powders }\end{array}$ & Description \\
\hline $\begin{array}{l}\text { LH-NDM } \\
\text { LH-SSMP }\end{array}$ & MH-NDM & Low heat (LH) or medium heat (MH) NDM with approximately 35\% protein content \\
LH-PP & MH-SSMP & LH or MH standardized skim milk powder (SSMP) independent of standardization material \\
LH34-PP & MH-PP & LH or MH SSMP with permeate powder (PP) \\
LH32-PP & MH34-PP & LH or MH SSMP with PP to contain 34\% protein content \\
LH30-PP & MH32-PP & LH or MH SSMP with PP to contain 32\% protein content \\
LH-ELP & MH30-PP & LH or MH SSMP with PP to contain 30\% protein content \\
LH34-ELP & MH-ELP & LH or MH SSMP with edible lactose powder (ELP) \\
LH32-ELP & MH34-ELP & LH or MH SSMP with ELP to contain 34\% protein content \\
LH30-ELP & MH32-ELP & LH or MH SSMP with ELP to contain 32\% protein content \\
\hline
\end{tabular}

Several methods have been reported to measure the heat stability of milk, such as the ethanol stability test (Sommer and Binney, 1923), oil bath method (Davies and White, 1966), and the viscosity measurement (Foissy and Kneifel, 1984; de Wit et al., 1986; Kieseker and Aitken, 1988; Nieuwenhuijse et al., 1988). Of these methods, the oil bath method, although somewhat subjective, remains a widely used tool for heat stability in academic research. As has been shown by previous researchers (Fox, 1982; Rattray and Jelen, 1996; Singh, 2004; Sievanen et al., 2008) for unconcentrated milk, a temperature of $140^{\circ} \mathrm{C}$ is a relevant temperature for testing the heat stability of milk. At this temperature, milk coagulates in a reasonable timeframe for doing an assay and is also below the flash temperature of the commonly used oils.

The heat coagulation time (HCT) was determined following the method described by Davies and White (1966) with some modifications: $2.5 \mathrm{~mL}$ of milk was heated in tightly capped, 100-mm-long glass tubes, each with a 13-mm i.d. The tubes were fitted in a rocker and immersed in an oil bath containing heated mineral oil controlled at $140^{\circ} \mathrm{C}$. The $\mathrm{HCT}$ was recorded as the time between immersing the samples in the hot oil bath and the onset of visible clots.

\section{Statistical Analyses}

Results were evaluated using ANOVA and multiple linear regression in both Minitab (Minitab Inc., State College, PA) and Data Desk (Data Description Inc., Ithaca, NY) statistical software. Possible predictors of heat stability included in the model were powder type (LH, MH), protein level $(30,32,34$, and $35.5 \%)$, standardization material (ELP and PP), and $\mathrm{pH}$. All experiments for LH-NDM, MH-NDM, LH-SSMP, and MH-SSMP at unadjusted $\mathrm{pH}$ were performed in triplicate and repeated twice at adjusted $\mathrm{pH}$ values.

The heat stability of the aforementioned samples at unadjusted $\mathrm{pH}$ and adjusted $\mathrm{pH}$ values was analyzed separately using ANOVA with HCT as the response, and powder type, standardization material, protein content, $\mathrm{pH}$, and replicates as factors. In some analyses, data for LH-NDM and MH-NDM was excluded to create a factorial treatment structure that would allow for the study of possible interaction effects between protein levels $(30,32$, and $34 \%)$ and standardization material (ELP and PP).

\section{RESULTS AND DISCUSSION}

The $\mathrm{pH}$ of LH-NDM, MH-NDM, LH-SSMP, and MHSSMP samples was measured. It was observed that the $\mathrm{pH}$ of LH-PP or MH-PP was lower than the $\mathrm{pH}$ of the LH-NDM or MH-NDM, whereas the $\mathrm{pH}$ of LH-ELP or MH-ELP was higher than the $\mathrm{pH}$ of LH-NDM or MH-NDM. Therefore, the $\mathrm{pH}$ of PP and ELP powders was determined by reconstituting PP and ELP in water to contain $6 \%$ TS; UF permeate usually contains TS in the range of 5.5 to 6.0. After reconstitution, the $\mathrm{pH}$ of the permeate sample was observed to be 5.26 , whereas the $\mathrm{pH}$ of the ELP was determined to be 5.53. This led to further investigation with the manufacturer of PP. It was determined that the manufacturer adjusted the $\mathrm{pH}$ of the milk before UF, which resulted in acidic permeate. Furthermore, we discovered that it is not uncommon in the industry to make this adjustment.

During the course of this project, we analyzed PP obtained from the UF of skim milk with no $\mathrm{pH}$ adjustment of milk. In this analysis, it was observed that the $\mathrm{pH}$ of this reconstituted PP containing $6 \%$ TS was 6.7 and LH30-PP had enhanced heat stability when compared with the reconstituted LH-NDM (unstandardized milk; Table 3). However, for the current project, we used commercial permeate.

\section{Heat Stability at Unadjusted $\mathrm{pH}$}

Reconstituted LH Milk. Mean HCT value for LHNDM was higher than the HCT values obtained for LH- 
Table 3. Heat stability of reconstituted milk made from low-heat NDM (LH-NDM) and reconstituted milk made from standardized lowheat skim milk powder containing permeate (LH30-PP) adjusted to different $\mathrm{pH}$ values $(\mathrm{n}=2)$

\begin{tabular}{lcc}
\hline & \multicolumn{2}{c}{ Heat coagulation time $($ min; mean $\pm \mathrm{SD})$} \\
\cline { 2 - 3 } $\mathrm{pH}$ & LH-NDM & LH30-PP \\
\hline unadjusted $\mathrm{pH}(6.7)$ & $24.0 \pm 0.40$ & $28.0 \pm 0.42$ \\
6.4 & $9.41 \pm 0.14$ & $12.0 \pm 0.0$ \\
6.5 & $11.8 \pm 0.91$ & $14.2 \pm 0.40$ \\
6.6 & $16.0 \pm 2.12$ & $22.6 \pm 0.70$ \\
6.7 & $22.6 \pm 1.35$ & $27.5 \pm 0.35$ \\
6.8 & $8.0 \pm 0.40$ & $9.2 \pm 0.14$ \\
6.9 & $8.6 \pm 0.78$ & $8.4 \pm 0.10$ \\
7.0 & $12.0 \pm 2.72$ & $14.8 \pm 1.59$ \\
\hline
\end{tabular}

PP or LH-ELP. It was noted that a decrease in protein content resulted in a decrease in $\mathrm{HCT}$ values. Mean $( \pm \mathrm{SD}) \mathrm{HCT}$ for LH-NDM and LH30-PP was observed to be $24.5( \pm 0.61)$ and $16.3( \pm 0.16) \mathrm{min}$, respectively. Mean $( \pm \mathrm{SD})$ HCT for LH-NDM and LH30-ELP was observed to be $24.5( \pm 0.61)$ and $20.60( \pm 1.38) \mathrm{min}$, respectively. The higher heat stability of LH-NDM may be attributed to the maximum heat stability at native $\mathrm{pH}$ (6.7), whereas the low heat stability of LH30-PP may be attributed to its low $\mathrm{pH}$ (6.52) or the high $\mathrm{pH}$ (6.75) of LH30-ELP. Similar observations for maximum heat stability at a native $\mathrm{pH}$ have been reported (Holt et al., 1978). These authors reported in an extensive survey that the heat stability of bulk Scottish milk and the $\mathrm{pH}$ of maximum stability coincided with the native $\mathrm{pH}$. For LH-NDM or LH-SSMP reconstituted samples, maximum heat stability was observed to be at native $\mathrm{pH}$ and less heat stability was observed when the $\mathrm{pH}$ of the samples was changed by standardization to either lower or higher $\mathrm{pH}$.

Reconstituted $\mathbf{M H}$ Milk. Mean HCT value for MHNDM was slightly higher than the HCT values obtained for reconstituted MH-ELP. The mean $( \pm$ SD $)$ HCT value for MH-NDM was $9.3( \pm 0.13)$ min, whereas $\mathrm{HCT}$ values for MH34-ELP, MH32-ELP, and MH30-ELP were 9.01 $( \pm 0.43), 8.43( \pm 0.12)$, and $7.9( \pm 0.4) \mathrm{min}$, respectively. Higher mean $\pm \mathrm{SD} \mathrm{HCT}$ values were observed for MH-PP compared with MH-ELP. The effect of protein content was dependent upon standardization material. Mean $( \pm \mathrm{SD})$ HCT values for MH34-PP, MH32-PP, and MH30-PP were $19.2( \pm 0.20), 18.5( \pm 0.96)$, and 14.3 $( \pm 0.15)$ min, respectively. At unadjusted $\mathrm{pH}, \mathrm{HCT}$ values for MH-NDM and MH-SSMP were lower than for LH-NDM and LH-SSMP respectively. The difference in heat stability at unadjusted $\mathrm{pH}$ of the LH-NDM, LH-SSMP, MH-NDM, and MH-SSMP samples may be attributed to the difference in the preheating of milk before powder manufacturing. It has been reported that preheating conditions shift maximum heat stability to
Table 4. The ANOVA of heat coagulation time at unadjusted $\mathrm{pH}$ (controls excluded)

\begin{tabular}{lrrr}
\hline Source & df & F-ratio & $P$-value \\
\hline Treatment $^{1}$ & 3 & 453.06 & $<0.0001$ \\
Protein level & 1 & 51.31 & $<0.0001$ \\
pH & 1 & 0.28 & 0.6002 \\
Treatment $\times$ protein level & 3 & 3.42 & 0.0327 \\
Replicate & 2 & 2.62 & 0.0926 \\
Error & 25 & & \\
Total & 35 & & \\
\hline
\end{tabular}

${ }^{1}$ Treatment $=$ powder type and standardization material.

an acidic value (Rose, 1961; Newstead et al., 1975). A higher heat treatment is given to MH NDM powders to denature whey protein compared with the heat treatment given to LH NDM powders.

Statistical Analysis. For analysis at unadjusted $\mathrm{pH}$, protein and $\mathrm{pH}$ were treated as continuous factors because they had linear relationships with HCT over the range of unadjusted $\mathrm{pH}$ and protein values in the experiment. For simplicity in some analyses, the powder type and standardization material factors were combined into 1 treatment factor with 4 levels: LH-PP, LH-ELP, MH-PP, and MH-ELP.

The ANOVA of HCT at unadjusted $\mathrm{pH}$ for LH-SSMP and MH-SSMP is shown in Table 4. At unadjusted $\mathrm{pH}, \mathrm{HCT}$ was significantly related to protein content $(P<0.0001)$ and treatment $(P<0.0001)$, which is a combination of powder type and standardization material. After accounting for differences in protein among the samples, unadjusted $\mathrm{pH}$ did not significantly affect HCT $(P=0.60)$. Because LH or MH NDM powder standardization with PP or ELP changed the protein content and (upon reconstitution) $\mathrm{pH}$ values of both

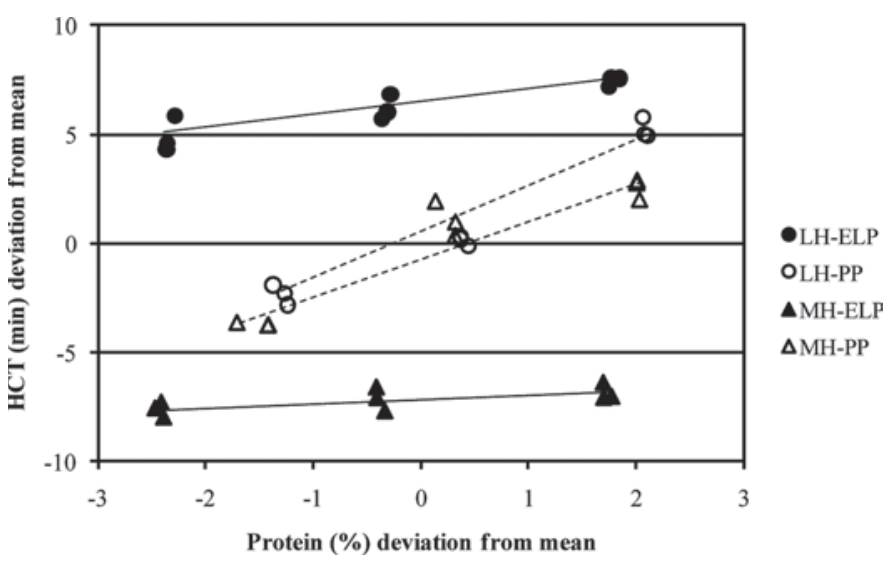

Figure 2. Effect of protein content on the heat coagulation time (HCT, adjusted for replicate differences) of reconstituted milk made from low-heat standardized skim milk powder and medium-heat standardized skim milk powders with permeate powder ( $\mathrm{LH}-\mathrm{PP}$ and $\mathrm{MH}-$ $\mathrm{PP}$, respectively) or edible lactose powder (LH-ELP, MH-ELP). 
Table 5. Effect of each $1 \%$ decrease in protein on mean heat coagulation time (min)

\begin{tabular}{lcccc}
\hline Treatment $^{1}$ & Estimate $^{2}$ & $\begin{array}{l}\text { Lower } \\
\text { limit }^{2}\end{array}$ & $\begin{array}{l}\text { Upper } \\
\text { limit }^{2}\end{array}$ & SD $^{3}$ \\
\hline LH-PP & -1.63 & -0.59 & -2.67 & $\mathrm{a}$ \\
MH-PP & -1.37 & -0.54 & -2.20 & $\mathrm{a}$ \\
LH-ELP & -0.69 & -0.22 & -1.15 & $\mathrm{ab}$ \\
MH-ELP & -0.25 & 0.23 & -0.73 & $\mathrm{~b}$ \\
\hline
\end{tabular}

${ }^{1}$ Treatments: LH-PP $=$ reconstituted milk made from low-heat standardized skim milk powder with permeate powder; $\mathrm{MH}-\mathrm{PP}=$ reconstituted milk made from medium-heat standardized skim milk powder with permeate powder; LH-ELP $=$ reconstituted milk made from lowheat milk standardized skim milk powder with edible lactose powder; MH-ELP = reconstituted milk made from medium-heat standardized skim milk powder with edible lactose powder.

${ }^{2}$ Estimate is the change in mean heat coagulation time for each $1 \%$ decrease in protein; limits are the $99 \%$ confidence bounds associated with the estimate.

${ }^{3}$ Samples sharing the same letter do not have a statistically significant difference in the effect of protein on heat coagulation time.

powders, it is assumed that standardization material, protein level, and $\mathrm{pH}$ level are all related. This makes it more difficult to determine which of these factors affects HCT; however, based on this analysis, protein has a much more significant effect on HCT than unadjusted $\mathrm{pH}$. This could be due to the small range of $\mathrm{pH}$ values present in the samples (e.g., with increasing level of PP standardization in LH NDM, $\mathrm{pH}$ ranged from 6.7 to 6.52 in LH-NDM and LH30-PP, respectively).

A linear regression analysis based on the model from Table 4 was used to estimate the effect of these factors on HCT. Because the effect of protein content on HCT depends on powder type and standardization material, a separate estimate of the protein content effect is given for each combination of powder type and standardization material. Estimates of the effect of a 1\% decrease in protein content caused by protein standardization in LH-PP, MH-PP, LH-ELP, and MH-ELP are summarized in Table 5. For example, a 1\% decrease in protein (LH-PP) caused a decrease between 0.59 to $2.67 \mathrm{~min}$ in mean HCT. All estimates given in Table 5 are with $99 \%$ confidence. The letters on the right indicate samples that had a significantly different effect of protein on HCT. Samples that share the same letter did not have significantly different protein effects. Using estimates shown in Table 5, we see that whereas a decrease in protein content reduced HCT in 3 of the treatments, protein content had no significant effect on HCT in MH-ELP.

Figure 2 is a partial regression plot of the protein effect on HCT for each of the 4 treatments. The variables in Figure 2 have been adjusted for the presence of different replicates and $\mathrm{pH}$ values in our model. The variable on the vertical axis is the deviation of the model adjusted HCT from its mean. The horizontal axis is the deviation of the model adjusted protein from its mean. (The small variation in protein level within each treatment group is a result of the statistical adjustment for having natural $\mathrm{pH}$ in the model.)

Because HCT changes with protein standardization, different protein levels will have a different mean HCT. As an example, results in Table 6 show the mean predicted HCT for samples with $32 \%$ protein and $6.7 \mathrm{pH}$, values near the center of the protein and $\mathrm{pH}$ ranges. The letters on the right indicate which samples had a significantly different mean HCT for $32 \%$ protein and $6.7 \mathrm{pH}$. Samples that share the same letter were not significantly different based on Tukey intervals with 99\% simultaneous confidence. At pH 6.7, LH32-ELP had significantly greater heat stability than MH32-ELP or MH32-PP; MH32-ELP has significantly lower heat stability than the 3 other treatments.

\section{Heat Stability at Adjusted pH}

We selected a $\mathrm{pH}$ range of 6.3 to 7.0 because this $\mathrm{pH}$ range accounts for a typical bovine $\mathrm{pH}$ (6.6-6.7). It also accounts for the variability that can be associated with quality and heating effect (Walstra and Jenness, 1984).

Reconstituted LH Milk. The LH-NDM and LHSSMP exhibited an increase in heat stability as $\mathrm{pH}$ increased from 6.3 to 6.7 . The minimum heat stability for both LH-NDM and LH-SSMP was found to be at $\mathrm{pH}$ 6.9. Additionally, a heat stability increase was observed as $\mathrm{pH}$ increased to 7.0. Maximum heat stability for both LH-NDM and LH-SSMP was observed to be at $\mathrm{pH}$ 6.7, as shown in Figure 3. Similar observations for maximum heat stability at native $\mathrm{pH}$ during most of the year have been reported (Holt et al., 1978) over the $\mathrm{pH}$ range of $6.5-7.4$ and over the $\mathrm{pH}$ range of $6.3-7.1$ (Sindhu and Singh, 1987). Both LH-NDM and LH-

Table 6. Model estimated mean heat coagulation time (HCT; min) at $32 \%$ protein and $6.7 \mathrm{pH}$ for each treatment

\begin{tabular}{lcc}
\hline & Mean & \\
Treatment $^{1}$ & HCT & SD $^{2}$ \\
\hline LH-ELP & 22.10 & $\mathrm{a}$ \\
LH-PP & 18.06 & $\mathrm{ab}$ \\
MH-PP & 17.79 & $\mathrm{~b}$ \\
MH-ELP & 8.60 & $\mathrm{c}$ \\
\hline
\end{tabular}

${ }^{1} \mathrm{LH}-\mathrm{PP}=$ reconstituted milk made from low-heat standardized skim milk powder with permeate powder; $\mathrm{MH}-\mathrm{PP}=$ reconstituted milk made from medium-heat standardized skim milk powder with permeate powder; LH-ELP = reconstituted milk made from low-heat milk standardized skim milk powder with edible lactose powder; MH-ELP $=$ reconstituted milk made from medium-heat standardized skim milk powder with edible lactose powder.

${ }^{2}$ Samples sharing the same letter do not have a statistically significant difference in HCT at $32 \%$ protein and $6.7 \mathrm{pH}$. 


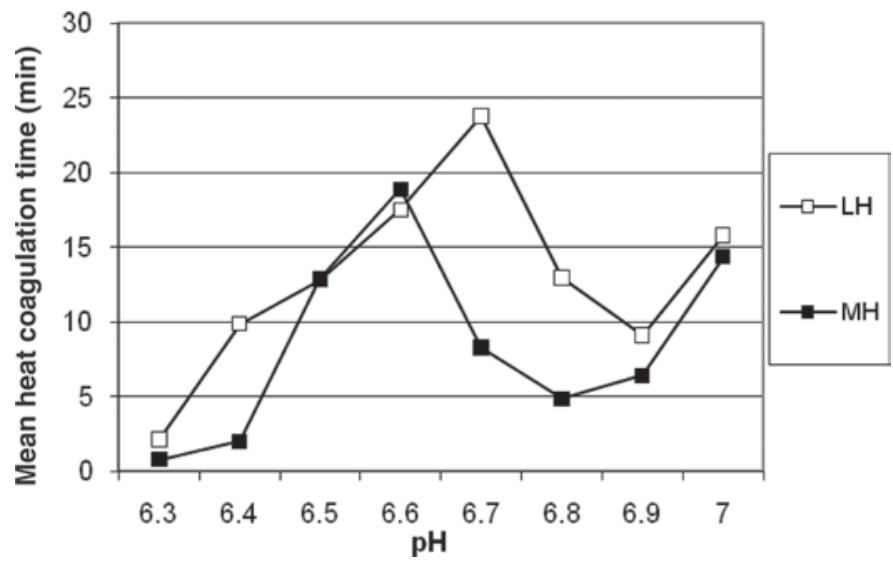

Figure 3. Effect of $\mathrm{pH}$ on the heat coagulation time (HCT) of reconstituted milk made from low-heat $(\mathrm{LH})$ and medium-heat $(\mathrm{MH})$ powder averaged across standardization material and powder type.

SSMP showed a typical type A milk HCT pH profile. It is well established that 2 types of milk exist: type A and type B (Tessier and Rose, 1964). In a typical type A milk, heat stability first increases with an increase in $\mathrm{pH}$ from 6.3 to 6.7 and then decreases at or up to 6.9 , followed by an increase as the milk reaches $\mathrm{pH} 7.0$; in type B milk, HCT increases with respect to $\mathrm{pH}$ (Rose, 1961; Fox, 1982).

Although statistically not significant, a trend was observed toward higher heat stability for SSMP with an increasing amount of PP in maximum heat stability region. For example, a higher HCT value was observed for LH30-PP followed by HCT values of LH32-PP and LH34-PP compared with LH-NDM. Similar observations were made by Rattray and Jelen (1996) in skim milk protein standardized with skim milk UF permeate or sweet whey UF permeate over a $\mathrm{pH}$ range of 6.4 to 7.1; however, our results differed at $\mathrm{pH}$ minima. Kelly (2006) reported similar results. In addition, Rattray and Jelen (1996) reported that the higher heat stability of milk protein standardized with either skim milk UF permeate or sweet whey UF permeate may be attributed to its low total calcium. From Table 7, it is clear that LH-SSMP has reduced total calcium compared with the total calcium in LH-NDM. However, the ratio of total calcium to protein was slightly higher in LH-PP compared with LH-ELP. Permeate contains nonprotein nitrogen and minerals when compared with lactose; therefore, we attributed the enhanced heat stability of LH-PP over adjusted $\mathrm{pH}$ to the buffering capacity of the nonprotein nitrogen fraction of permeate powder compared with ELP. A positive correlation between nonprotein nitrogen and heat stability was reported (Robertson and Dixon, 1969). The addition of urea in normal milk comprises more than $50 \%$ of the nonprotein nitrogen fraction and leads to an increase in the
Table 7. Total calcium content of low-heat NDM (LH-NDM) and low-heat standardized skim milk powder with edible lactose powder (LH-ELP) or low-heat standardized skim milk powder with permeate powder $(\mathrm{LH}-\mathrm{PP})^{1}$

\begin{tabular}{lc}
\hline Sample $^{2}$ & Total calcium $(\mathrm{mg} / \mathrm{L} ;$ mean $\pm \mathrm{SD})$ \\
\hline LH-NDM & $1,100 \pm 7.1$ \\
LH34-ELP & $1,060 \pm 10.34$ \\
LH32-ELP & $994 \pm 4.24$ \\
LH30-ELP & $942 \pm 5.66$ \\
LH34-PP & $1,070 \pm 12.0$ \\
LH32-PP & $1,014 \pm 5.66$ \\
LH30-PP & $964 \pm 11.3$ \\
\hline${ }^{1} \mathrm{n}=3$. & \\
${ }^{2}$ LH-NDM = reconstituted low-heat NDM powder; LH34-ELP, LH32- \\
ELP, LH30-ELP = reconstituted milk made from low-heat standard- \\
ized skim milk powder with edible lactose powder to contain 34, 32, \\
and 30\% protein content, respectively; LH34-PP, LH32-PP, LH30-PP \\
= reconstituted milk made from low-heat standardized skim milk pow- \\
der with permeate powder to contain 34, 32, and 30\% protein content, \\
respectively.
\end{tabular}

heat stability (de Koning et al., 1974). Enhanced heat stability of LH-PP was observed around maximum heat stability and no effect was observed at $\mathrm{pH} 6.8$ or 6.9. Similar to our results, Muir and Sweetsur (1977) reported that urea increased the HCT at maximum heat stability and no effect was seen at minimum heat stability until a high level of urea ( $>40 \mathrm{mg} / 100 \mathrm{~mL}$ of milk) was used. Fox et al. (1980) suggested that the higher heat stability of milk containing urea may be due to the buffering capacity of urea following thermal decomposition. A higher heat stability in protein-standardized LH-PP compared with LH-ELP was observed. Rajput et al.(1984) reported that heat-induced acidity (HIA) of milk decreased with added levels of urea $(0,25,50$, $200 \mathrm{mg} / 100 \mathrm{~mL}$ ) and was attributed to low degradation of urea with increased heating time $(2,5$, and 10 $\min )$ at $140^{\circ} \mathrm{C}$. The decreased HIA by urea contributed to the increased heat stability of milk. Furthermore, in a milk salt solution, the HIA was decreased by the addition of urea $(25 \mathrm{mg} / 100 \mathrm{~mL}$ of milk) followed by a combination of urea and lactose $(25 \mathrm{mg} / 100 \mathrm{~mL}$ of milk and $4.6 \%$ lactose) and increased by lactose ( $4.6 \%$ lactose).

Similarly, we observed less reduction in $\mathrm{pH}$ (original $\mathrm{pH}-\mathrm{pH}$ after coagulation of cold samples) for reconstituted PP $(\mathrm{pH}=6.7)$ standardized samples compared with the ELP standardized samples. Fox (1981) reported a decrease in $\mathrm{pH}$ as the primary cause of milk coagulation during heating. Some factors responsible for a decrease in $\mathrm{pH}$ upon heating include formation of organic acids from decomposition of lactose during heating, release of $\mathrm{CO}_{2}$, precipitation of calcium phosphate, and release of $\mathrm{H}^{+}$(Walstra and Jenness, 1984).

A slightly lower heat stability for SSMP with an increasing amount of ELP was observed in maximum heat 
stability region compared with LH-NDM. Although statistically not significant, a trend toward higher heat stability was observed for LH-NDM, followed by LH34ELP, LH32-ELP, and LH30-ELP. This trend was applicable for all $\mathrm{pH}$ values except in the region of minimum $(\mathrm{pH}=6.8$ or 6.9$)$. Similar observations of enhanced heat stability at $\mathrm{pH}$ minima were made by Fox and Hearn (1978) in milk diluted with water $(40 \mathrm{~mL}$ of water/100 $\mathrm{mL}$ of milk).

Reconstituted $\mathbf{M H}$ Milk. Both MH-NDM and MH-SSMP showed a typical type A milk HCT-pH profile similar to LH-NDM and LH-SSMP. However, maximum heat stability for MH-NDM and MH-SSMP was found to be at $\mathrm{pH} 6.6$. We observed $\mathrm{pH}$ values 6.7 , 6.65, 6.59, and 6.52 for MH-NDM, MH34-PP, MH32-PP and MH30-PP respectively. Thus, the lowering of the $\mathrm{pH}$ value from 6.7 to 6.59 actually increased the heat stability as it brought the $\mathrm{pH}$ value down to an optimal $\mathrm{pH}$ value for maximum heat stability. However, $\mathrm{pH}$ values were found to increase slightly with an increase in the degree of NDM powder protein standardization with ELP (e.g., pH values of $6.72,6.73$, and 6.75 were observed for MH34-ELP, MH32-ELP, and MH30-ELP, respectively). Therefore, enhanced heat stability was observed for MH-PP samples around maximum heat stablility $(\mathrm{pH}=6.6)$ and the reverse trend was observed at $\mathrm{pH}$ minima. However, for MH-ELP samples, a slight increase in heat stability at $\mathrm{pH}$ minima was observed, similar to LH-ELP.

Statistical Analysis. Results in Table 8 show the ANOVA for HCT in LH-NDM, LH-SSMP, MH-NDM, and MH-SSMP at adjusted $\mathrm{pH}$. The combinations of powder type and standardization material $(P=0.0003)$, powder type and $\mathrm{pH}(P<0.0001)$, and standardization material and $\mathrm{pH}(P<0.0001)$ were found to affect heat stability significantly. Because the protein level for the LH-NDM or MH-NDM differed from LH-SSMP or MH-SSMP, the effect of protein content on HCT had to be compared across the 7 combinations of protein and standardization (unstandardized/35.5\%, ELP $/ 34 \%$, $\mathrm{ELP} / 32 \%, \mathrm{ELP} / 30 \%, \mathrm{PP} / 34 \%, \mathrm{PP} / 32 \%$, and $\mathrm{PP} / 30 \%$ ). To accomplish this in the statistical model, the protein factor was nested within the standardization factor. Mean heat stability did not differ significantly across these 7 protein groups $(P=0.3466)$. Newstead (1977) reported that alternating the protein concentration had no effect on heat stability during any season. Anema et al. (1993) reported that increased protein concentration at a constant mineral concentration had negligible effect on HCT. Similarly, no correlation between the protein content and HCT was observed in goat milk (Mukherjee, 1993). Based on our results, when $\mathrm{pH}$ is adjusted to values between 6.3 and 7.0 , we conclude that decreasing protein content with an increasing level

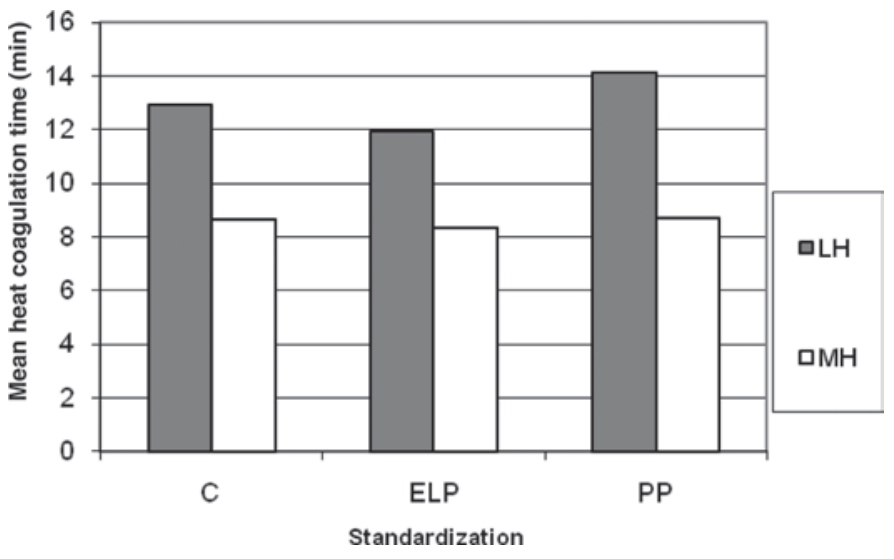

Figure 4. Effect of powder type and standardization material on the heat coagulation time (HCT) of reconstituted milk made from low-heat (LH) standardized skim milk powder and medium-heat (MH) standardized skim milk powder samples averaged across adjusted $\mathrm{pH}$. Standardization: $\mathrm{C}=$ control/unstandardized; ELP $=$ edible lactose powder; $\mathrm{PP}=$ permeate powder.

of standardization does not significantly influence heat stability.

Figure 4 shows the effect of powder type and standardization material on HCT from the ANOVA in Table 8. Tukey intervals with $99 \%$ simultaneous confidence were used for LH-NDM, LH-PP, LH-ELP, MH-NDM, MHPP, and MH-ELP in Table 9. The LH-SSMP samples had a higher mean HCT than the MH-SSMP samples for all standardization material. Among the LH NDM powder samples, LH-PP had a significantly higher mean HCT than LH-ELP. No significant difference in heat stability was observed between the MH-NDM and MH-PP or MH-ELP.

In Table 10, Tukey intervals with 99\% simultaneous confidence were used to separate the powder type by $\mathrm{pH}$ treatment combinations. Independent of protein standardization, the LH-SSMP had a higher mean HCT than MH-SSMP at $\mathrm{pH} 6.4,6.7,6.8$, and 6.9. Although the MH-SSMP had a slightly higher mean HCT

Table 8. The ANOVA of heat coagulation time in $\mathrm{pH}$-adjusted samples (controls included)

\begin{tabular}{lrr}
\hline Source & df & $P$-value \\
\hline Replicate & 1 & $<0.0001$ \\
Powder type & 1 & $<0.0001$ \\
Standardization material & 2 & $<0.0001$ \\
Protein level (standardization material) & 5 & 0.3466 \\
pH & 7 & $<0.0001$ \\
Powder type $\times$ standardization material & 2 & 0.0003 \\
Powder type $\times$ protein level & 4 & 0.3925 \\
Powder type $\times$ pH & 7 & $<0.0001$ \\
Standardization material $\times \mathrm{pH}$ & 14 & $<0.0001$ \\
Protein $\times$ pH & 35 & 0.2346 \\
Error & 143 & \\
Total & 221 & \\
\hline
\end{tabular}


Table 9. Model estimated mean heat coagulation time (HCT; min) for each pairing of powder and standardization for $\mathrm{pH}$-adjusted samples

\begin{tabular}{lcc}
\hline & Mean & \\
Treatment $^{1}$ & HCT & $\mathrm{SD}^{2}$ \\
\hline LH-PP & 14.15 & $\mathrm{a}$ \\
LH-NDM & 12.95 & $\mathrm{ab}$ \\
LH-ELP & 11.92 & $\mathrm{~b}$ \\
MH-PP & 8.707 & $\mathrm{c}$ \\
MH-NDM & 8.649 & $\mathrm{c}$ \\
MH-ELP & 8.328 & $\mathrm{c}$ \\
\hline
\end{tabular}

${ }^{1} \mathrm{LH}-\mathrm{PP}=$ reconstituted milk made from low-heat standardized skim milk powder with permeate powder; LH-NDM = reconstituted milk made from low-heat NDM; LH-ELP = reconstituted milk made from low-heat milk standardized skim milk powder with edible lactose powder; MH-PP $=$ reconstituted milk made from medium-heat standardized skim milk powder with permeate powder; $\mathrm{MH}-\mathrm{NDM}=$ reconstituted milk made from medium-heat NDM; MH-ELP = reconstituted milk made from medium-heat standardized skim milk powder with edible lactose powder.

${ }^{2} \mathrm{SD}$ : Samples sharing the same letter do not have statistically significant differences.

than LH-SSMP at $\mathrm{pH}$ 6.6, this was not statistically significant. At all other $\mathrm{pH}$ levels tested, there was no significant difference between the HS of the reconstituted LH-SSMP and MH-SSMP.

For LH-NDM and LH-SSMP samples, mean HCT increased significantly at each $\mathrm{pH}$ interval until HCT peaked at $\mathrm{pH}$ 6.7. Mean HCT significantly decreased in each $\mathrm{pH}$ interval from 6.7 to 6.9 before the mean $\mathrm{HCT}$ increased again from $\mathrm{pH} 6.9$ to 7.0. For MH-NDM and MH-SSMP samples, mean HCT did not increase significantly between $\mathrm{pH} 6.3$ and 6.4. The mean HCT increased rapidly from $\mathrm{pH} 6.4$ to a peak of $\mathrm{pH}$ 6.6. The mean HCT decreased significantly from $\mathrm{pH} 6.6$ to 6.8 , did not change significantly between $\mathrm{pH} 6.8$ and 6.9 , and increased from $\mathrm{pH} 6.9$ to 7.0. Independent of standardization material, maximum heat stability for MH-SSMP lies at a lower $\mathrm{pH}$ when compared with LHSSMP. This may be attributed to a higher preheating condition given to MH NDM compared with LH NDM during its manufacture. Similarly, preheating unconcentrated milk at $90^{\circ} \mathrm{C}$ for 10 min shifted the maximum $\mathrm{pH}-\mathrm{HCT}$ profile to a more acidic $\mathrm{pH}$, as was observed by Tan-Kintia and Fox (1999).

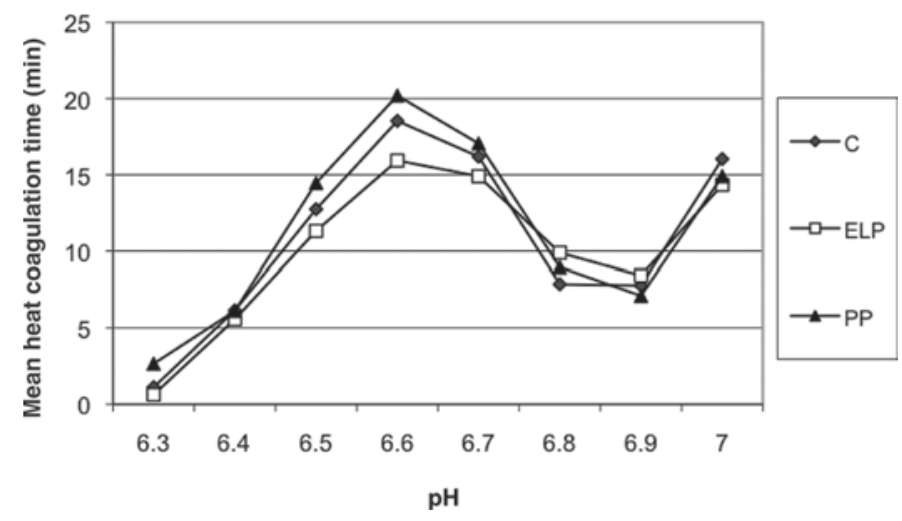

Figure 5. Effect of standardization material and $\mathrm{pH}$ on the heat coagulation time (HCT) of reconstituted milk made from low-heat (LH) or medium-heat (MH) nonfat dry milk powder (LH-NDM and MH-NDM, respectively), $\mathrm{LH}$ or $\mathrm{MH}$ standardized skim milk powder with edible lactose powder (LH-ELP and MH-ELP, respectively), or standardized skim milk powder with permeate powder (LH-PP, MH-PP) samples. Results averaged across LH and MH samples. Standardization: $\mathrm{C}=$ control (unstandardized); ELP = edible lactose powder; $\mathrm{PP}=$ permeate powder.

Figure 5 shows the effect of standardization material and $\mathrm{pH}$ on HCT. In Table 11, Tukey intervals with $99 \%$ simultaneous confidence were used to separate the HCT levels based on standardization material within each $\mathrm{pH}$ value. Because of the large number of combinations, differences in HCT across $\mathrm{pH}$ levels were not tested. The Tukey intervals show that samples standardized with PP had higher mean HCT than those standardized with ELP only at $\mathrm{pH} 6.5$ and 6.6. At all other $\mathrm{pH}$ levels, no significant difference was observed between mean HCT among the standardization material.

Although these differences are not noted on Table 11, the Tukey intervals also revealed that mean HCT for samples standardized with PP, independent of type of powder, peaked at $\mathrm{pH}$ 6.6. For unstandardized and ELP standardized samples, mean HCT increased between $\mathrm{pH}$ 6.5 and 6.6 , but was not significantly different between $\mathrm{pH} 6.6$ and 6.7. It is difficult to differentiate between HCT at pH 6.6 and 6.7 for the LH-NDM or MH-NDM and LH-ELP or MH-ELP; the true peak HCT could be at either $\mathrm{pH} 6.6$ or 6.7 or somewhere in between.

Table 10. Model estimated mean heat coagulation time ( $\min )$ for each pairing of powder and adjusted $\mathrm{pH}$

\begin{tabular}{|c|c|c|c|c|c|c|c|c|}
\hline \multirow{2}{*}{$\begin{array}{l}\text { Reconstituted } \\
\text { sample }^{1}\end{array}$} & \multicolumn{8}{|c|}{$\mathrm{pH}$} \\
\hline & 6.3 & 6.4 & 6.5 & 6.6 & 6.7 & 6.8 & 6.9 & 7 \\
\hline LH-NDM & $2.1440^{\text {ae }}$ & $9.889^{\mathrm{d}}$ & $12.82^{\mathrm{b}}$ & $17.53^{\mathrm{ch}}$ & 23.81 & $12.960^{\mathrm{b}}$ & $9.119^{\mathrm{d}}$ & $15.80^{\mathrm{hi}}$ \\
\hline MH-NDM & $0.7926^{\mathrm{a}}$ & $2.009^{\mathrm{a}}$ & $12.86^{\mathrm{b}}$ & $18.91^{\mathrm{c}}$ & $8.28^{\mathrm{df}}$ & $4.847^{\mathrm{eg}}$ & $6.412^{\mathrm{fg}}$ & $14.38^{\mathrm{bi}}$ \\
\hline
\end{tabular}


Table 11. Model estimated mean heat coagulation time (min) for each pairing of standardization and adjusted $\mathrm{pH}$ (differences evaluated for each $\mathrm{pH}$ triplet only)

\begin{tabular}{lcccccccc}
\hline & \multicolumn{8}{c}{$\mathrm{pH}$} \\
\cline { 2 - 8 } $\begin{array}{l}\text { Type of } \\
\text { standardization }^{1}\end{array}$ & 6.3 & 6.4 & 6.5 & 6.6 & 6.7 & 6.8 & 6.9 & 7 \\
\hline SSMP-PP & $2.6560^{\mathrm{a}}$ & $6.119^{\mathrm{b}}$ & $14.46^{\mathrm{c}}$ & $20.19^{\mathrm{e}}$ & $17.05^{\mathrm{g}}$ & $8.959^{\mathrm{h}}$ & $7.102^{\mathrm{i}}$ & $14.90^{\mathrm{j}}$ \\
C & $1.1170^{\mathrm{a}}$ & $6.154^{\mathrm{b}}$ & $12.74^{\mathrm{cd}}$ & $18.53^{\mathrm{ef}}$ & $16.19^{\mathrm{g}}$ & $7.861^{\mathrm{h}}$ & $7.777^{\mathrm{i}}$ & $16.03^{\mathrm{j}}$ \\
SSMP-ELP & $0.6317^{\mathrm{a}}$ & $5.573^{\mathrm{b}}$ & $11.32^{\mathrm{d}}$ & $15.93^{\mathrm{f}}$ & $14.90^{\mathrm{g}}$ & $9.896^{\mathrm{h}}$ & $8.418^{\mathrm{i}}$ & $14.34^{\mathrm{j}}$ \\
\hline
\end{tabular}

${ }^{\mathrm{a}-\mathrm{j}}$ Samples sharing the same letter do not have statistically significant differences within the same $\mathrm{pH}$ level.

${ }^{1} \mathrm{SSMP}-\mathrm{PP}=$ standardized skim milk powder containing permeate powder; $\mathrm{C}=$ control $($ not standardized); SSMP-ELP $=$ standardized skim milk powder containing edible lactose powder.

\section{CONCLUSIONS}

Based on our observations, we conclude that heat stability is influenced by the type of NDM powder ( $\mathrm{LH}$ or $\mathrm{MH}$ ) and standardization material (PP or ELP). In some situations, $\mathrm{PP}$, besides containing minerals that cause destabilization of the milk system during heating, also contains a nonprotein nitrogen fraction that may impart heat stability to the milk system in the maximum heat stability region. Of the options studied, our results indicate that LH-PP provides the best heat stability for reconstituted milk.

\section{ACKNOWLEDGMENTS}

The authors acknowledge Dairy Management Inc. (Rosemont, IL) and California Dairy Research Foundation (Davis, CA) for their financial support. We thank the commercial dairy ingredient manufacturers for providing milk powder, lactose, and permeate samples.

\section{REFERENCES}

Anema, S. G., H. Singh, and L. K. Creamer. 1993. The relative importance of protein and mineral concentrations on the dissociation of $\kappa$-casein from the micelles in heated reconstituted skim milk. Int Dairy Fed. (Special Issue 9303):227-235.

AOAC. 1995. Official Method of Analysis. Vol. I. 16th ed. Association of Official Analytical Chemists, Gaitherburg, MD.

Brooks, I. B., G. A. Luster, and D. B. Easterly. 1970. A procedure for rapid determination of the major cations in milk by atomic absorption spectrophotometry. At. Absorpt. Newsl. 9:93-94.

Codex Alimentarius. 1999. Codex standard for milk powders and cream powder. http://www.codexalimentarius.net/download/ standards/333/CXS_207e.pdf Accessed September 20, 2010.

Davies, D. T., and J. C. D. White. 1966. The stability of milk protein to heat. 1. Subjective measurement of heat stability of milk. J. Dairy Res. 33:67-81.

de Koning, P. J., J. Koops, and P. J. van Rooijen. 1974. Some features of the heat stability of concentrated milk. III. Seasonal effects on the amounts of casein, individual whey proteins and NPN and their relation to variations in heat stability. Neth. Milk Dairy J. 28:186-202.

de Wit, J. N., G. Klarenbeek, and C. d. Graaf. 1986. Klaro-Graph: A new approach for the measurement of the viscosity, density and heat stability in milk and milk concentrates at temperatures up to $140^{\circ} \mathrm{C}$. Voedingsmiddelentechnologie $6: 25-27$.
Foissy, H., and W. Kneifel. 1984. An automatic method for measuring the heat coagulation time of milk powder solutions. J. Dairy Res. $51: 325-329$

Fox, P. F. 1981. Heat-induced changes in milk preceding coagulation. J. Dairy Sci. 64:2127-2137.

Fox, P. F. 1982. Heat-induced changes in milk preceding coagulation. Vol. 1. Pages 189-228 in Developments in Dairy Chemistry. P. F Fox, ed. Applied Science Publishers, London, UK.

Fox, P. F., and C. M. Hearn. 1978. Heat stability of milk: Influence of dilution and dialysis against water. J. Dairy Res. 45:149-157.

Fox, P. F., and P. A. Morrissey. 1977. Reviews of the progress of dairy science: The heat stability of milk. J. Dairy Res. 44:627-646.

Fox, P. F., B. M. Nash, T. J. Horan, J. O' Brien, and P. A. Morrissey. 1980. Effect of selected amides on heat-induced changes in milk. J. Dairy Res. 47:211.

Green, M. L., K. J. Scott, M. Anderson, M. C. A. Griffin, and F. A. Glover. 1984. Chemical characterization of milk concentrated by ultrafiltration. J. Dairy Res. 51:267-278.

Hardham, J. F. 1998. Effect of protein standardisation of milk by addition of UF milk permeate on the composition and storage stability of UHT processed milk. Aust. J. Dairy Technol. 53:22-27.

Harland, H. A., S. T. Coulter, and R. Jenness. 1955. Natural variation of milk serum proteins as a limitation of their use in evaluating the heat treatment of milk. J. Dairy Sci. 38:858-869.

Heck, J. M. L., H. J. F. van Valenberg, J. Dijkstra, and A. C. M. van Hooijdonk. 2009. Seasonal variation in the Dutch bovine raw milk composition. J. Dairy Sci. 92:4745-4755.

Holt, C., D. D. Muir, and A. W. M. Sweetsur. 1978. Seasonal changes in the heat stability of milk from creamery silos in south-west Scotland. J. Dairy Res. 45:183-190.

Jensen, K. 1988. Milk powders: Specifications in relation to the products to be manufactured. Pages 104-125 in International Dairy Federation Conference: Recombination of Milk and Milk Products. Special Issue 9001. IDF, Brussels, Belgium.

Kelly, P. 2006. Impact of ingredient protein standardization on recombined milk products. Proc. 27th Int. Congress and World Dairy Summit, Shanghai, China.

Kieseker, F. G., and B. Aitken. 1988. An objective method for determination of heat stability of milk powders. Aust. J. Dairy Technol. $43: 26-31$.

Kieseker, F. G., and D. Healey. 1996. Protein-adjusted non-fat milk powders. Aust. J. Dairy Technol. 51:83-88.

Muir, D. D., and A. W. M. Sweetsur. 1976. The influence of naturallyoccurring levels of urea on the heat stability of bulk milk. J. Dairy Res. 43:495-499.

Muir, D. D., and A. W. M. Sweetsur. 1977. Effect of urea on the heat coagulation of the caseinate complex in skim milk. J. Dairy Res. $44: 249-257$.

Mukherjee, D. 1993. Some factors affecting heat stability of goat milk Indian J. Dairy Sci. 46:307-310

Newstead, D. F. 1977. Effect of protein and salt concentration on the heat stability of evaporated milk. N. Z. J. Dairy Sci. Technol. $12: 171-175$ 
Newstead, D. F., W. B. Sanderson, and A. G. Baucke. 1975. The effects of heat treatment and $\mathrm{pH}$ on heat stability of recombined evaporated milk. N. Z. J. Dairy Sci. Technol. 10:113-118.

Ng-Kwai-Hang, K. F., J. F. Hayes, J. E. Moxley, and H. G. Monardes. 1987. Variation in milk protein concentrations associated with genetic-polymorphism and environmental-factors. J. Dairy Sci. 70:563-570.

Nieuwenhuijse, J. A., W. Timmermans, and P. Walstra. 1988. Calcium and phosphate partition during the manufacture of sterilized concentrated milk and their relations to the heat stability. Neth. Milk Dairy J. 42:387-421.

O'Connell, J. E., and P. F. Fox. 2003. Heat-induced coagulation of milk. Pages 879-930 in Advanced Dairy Chemistry. I. Proteins. 3rd ed. P. F. Fox and P. L. H. McSweeney, ed. Kluwer Academic, London, UK.

Rajput, Y. S., M. K. Bhavadasan, and N. C. Gangul. 1984. Effect of urea on heat-induced acidity and milk coagulation. N. Z. J. Dairy Sci. Technol. 19:49-54.

Rattray, W., and P. Jelen. 1996. Thermal stability of skim milk with protein content standardized by the addition of ultrafiltration permeates. Int. Dairy J. 6:157-170.

Robertson, N. H., and A. Dixon. 1969. The nitrogen fractions and heat stability of bovine milk. Agroanimalia 1:141-144.

Rose, D. 1961. Factors affecting the pH-sensitivity of the heat stability of milk from individual cows. J. Dairy Sci. 44:1405-1413.
Sievanen, K., T. Huppertz, and A. Kelly. 2008. Influence of added calcium chloride on the heat stability of unconcentrated and concentrated bovine milk. Int. J. Dairy Technol. 61:151-155.

Sikand, V., P. S. Tong, and J. Walker. 2008. Impact of protein standardization of milk powder with lactose or permeate on whey protein nitrogen index and heat classification. Dairy Sci. Technol. $88: 105-120$

Sindhu, J. S., and S. Singh. 1987. Effect fo $\mathrm{pH}$ on the heat stability of bovine milk from Zebu and crossbred cattle. J. Food Process. Preserv. 12:11-25.

Singh, H. 2004. Heat stability of milk. Int. J. Dairy Technol. 57:111119

Sommer, H. H., and T. H. Binney. 1923. A study of the factors that influence the coagulation of milk in the alcohol test. J. Dairy Sci. 6:176-197.

Tan-Kintia, R. H., and P. F. Fox. 1999. Effect of various preheat treatments on the heat stability of unconcentrated milk. Int. Dairy J. 9:219-225.

Tessier, H., and D. Rose. 1964. Influence of $\kappa$-casein and $\beta$-lactoglobulin on the heat stability of skim milk. J. Dairy Sci. 47:1047-1051.

Walstra, P., and R. Jenness. 1984. Dairy Chemistry and Physics. Wiley \& Sons Publishers, New York, NY. 